\title{
الاتصال الفعال في المؤسسة الاقتصادية الجزائرية
}

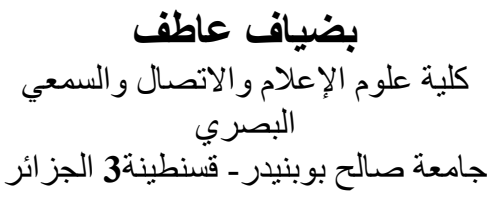

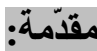

بعد الاتصال التنظيمي (المؤسساتي) ذا أهمية كبرى في وقتنا الحالي، كونه المحرك الأساسي الذي فئي يضمن بقاء واستقرار المؤسسات الاقتصادية كأنظمة الأنساء جزئية تنشط داخل نظام اجتماعي

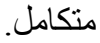

وهذا بطبيعة الحال راجع إلى مفهوم التغيير و الحاكمية التي أصبحت التنهات التهجها هذه المؤسسات، أي الانتقال من الاعتماد الإد

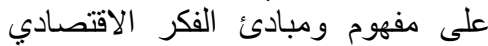

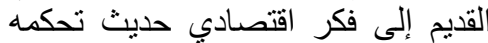

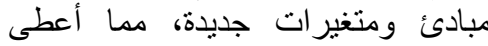

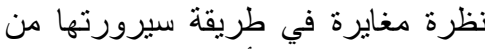

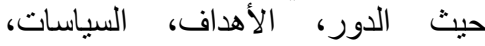
و الاستر اتيجيات المنتهجة.

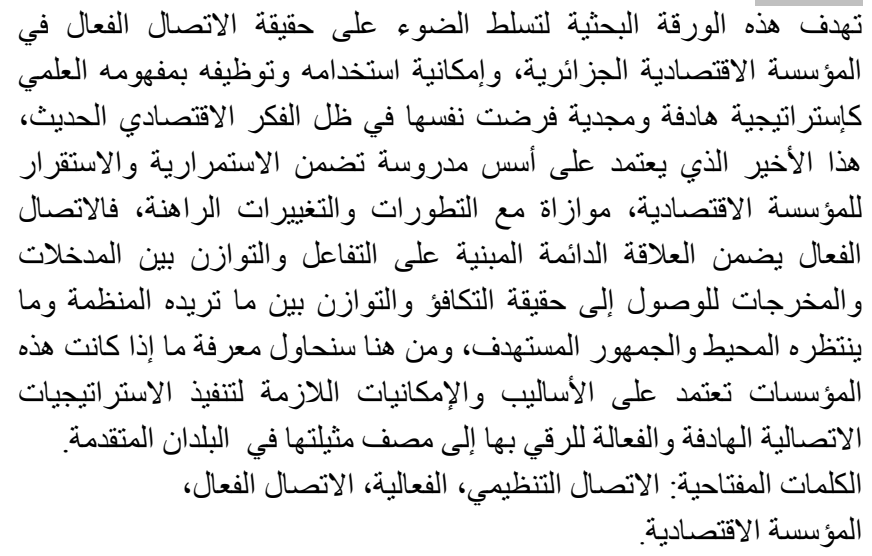

\section{Résumé:}

Cette étude vise à mettre la lumière sur la réalité de la communication efficace au sein de l'entreprise économique algérienne, ainsi que la possibilité de l'utiliser avec son concept scientifique en tant que stratégie efficace et qui s'est imposée dans la pensée économique moderne .

Cette dernière repose sur des bases bien étudiées qui garantissent la pérennité et la stabilité de l'entreprise économique, en même temps que les changements et les développements actuels. La communication efficace garantit une relation pérenne basée sur l'interaction et l'équilibre entre ce que la société cherche et ce que l'environnement et le public ciblé attendent .

De là, nous allons essayer de savoir si ces sociétés dépendent des méthodes et capacités nécessaires afin de mettre en œuvre la stratégie de communication efficace, dans le but de les faire atteindre le niveau des pays développés.

Mots-clés: communication organisationnelle, efficacité, la communication efficace, l'entreprise économique 


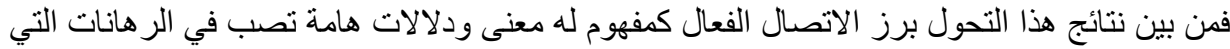

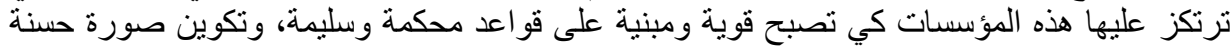

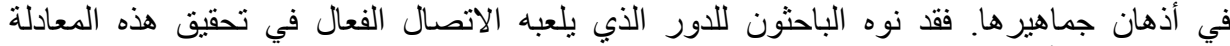

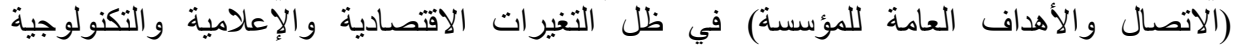
و والاجتماعية التي يشهدها العالم في وقتنا الحالي.

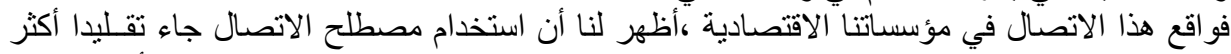

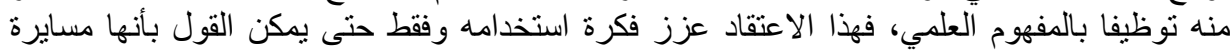

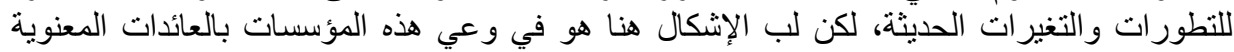

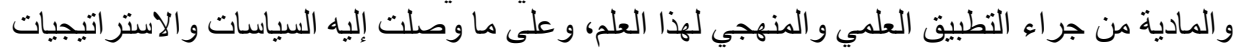

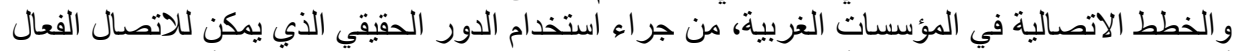

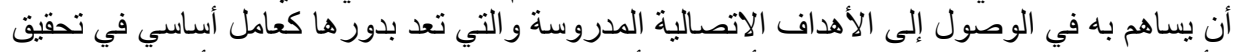

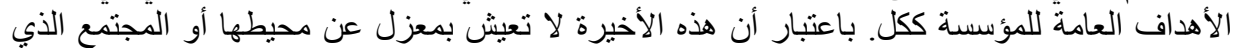

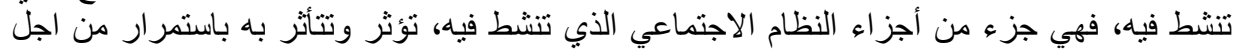

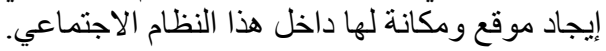

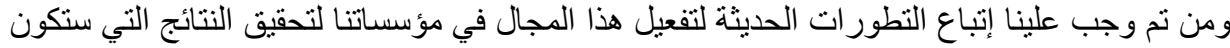

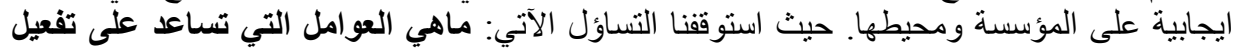
الاتصال في المؤسسة الاقتصادية ؟ الإنسة

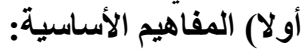

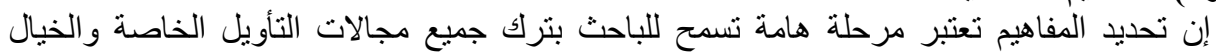

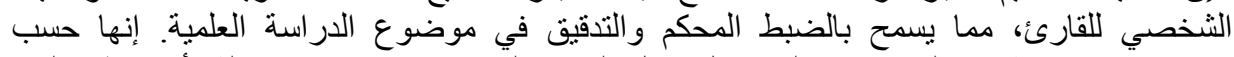

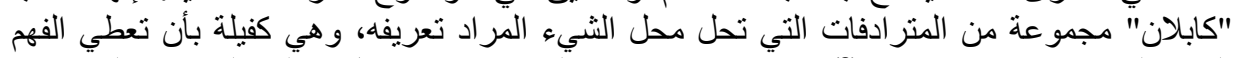

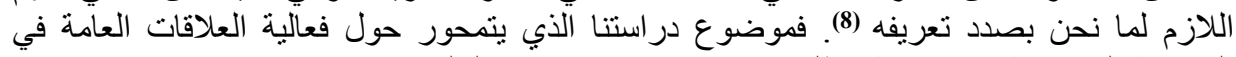

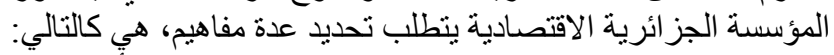

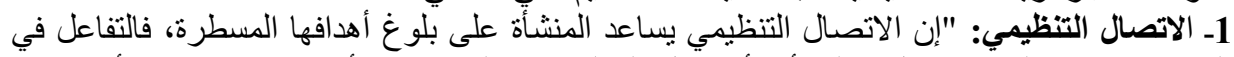

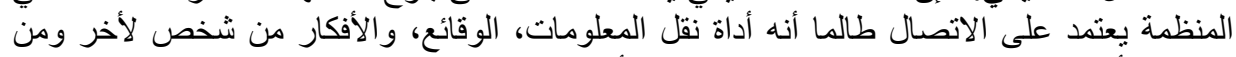

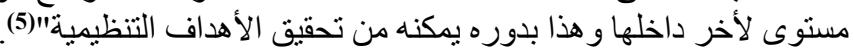

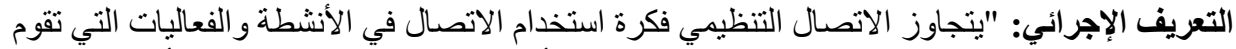

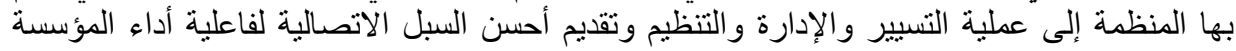

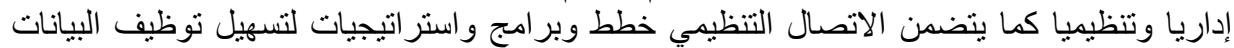

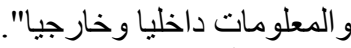

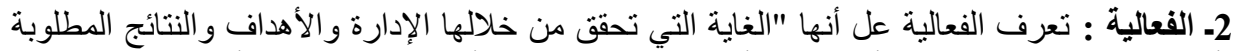

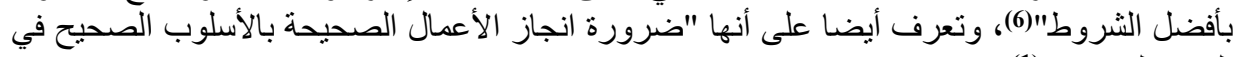

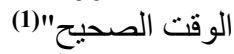

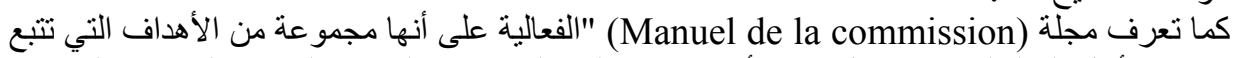

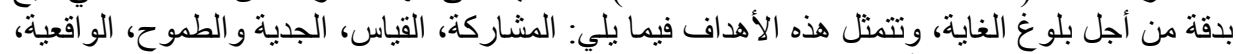

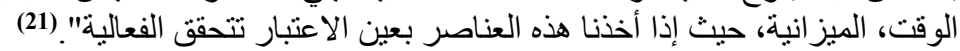

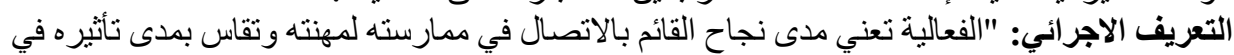

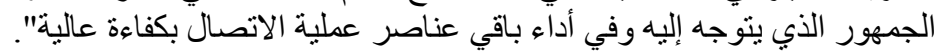

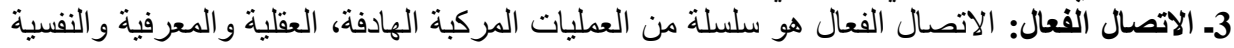

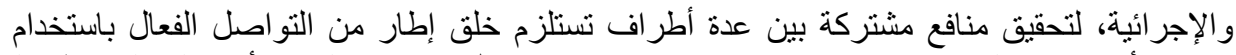

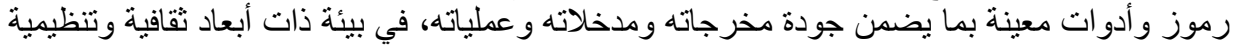
و اقتصادية ومادية" (16) 
التعريف الإجرائي: يعبر على الاتصال الفعال بمدى قدرة القائمين الدختصبن بالاتصال في المؤسسة

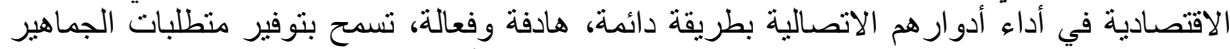

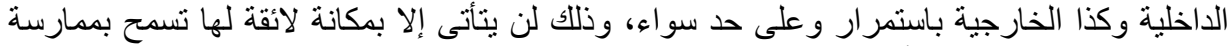

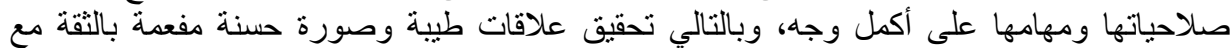

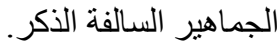

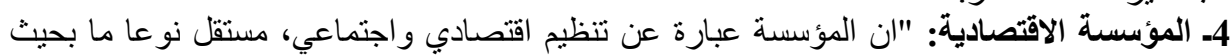

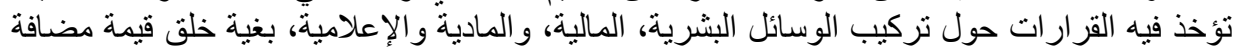

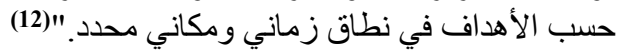

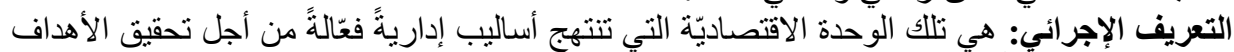

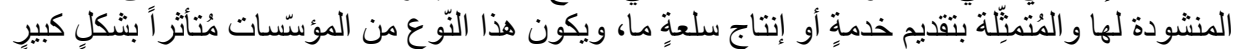

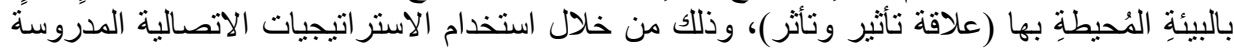
المنبثقة من معرفة كلية و عميقة للجماهير الداخلية و الخارجية ولئية وكذا المحيط.

ثانيا: الاتصال الفعال: الإل

إن نجاح الاتصال مر هون بإتباع التعليمات التالية:

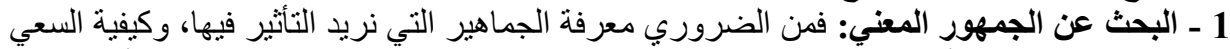

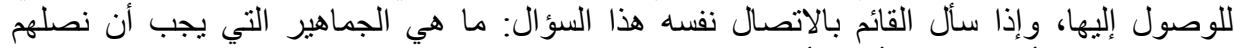

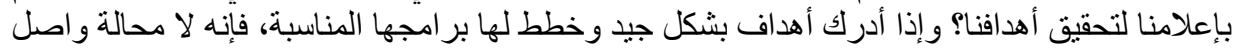
إلى جمهوره.

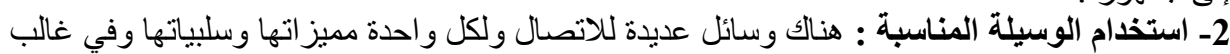

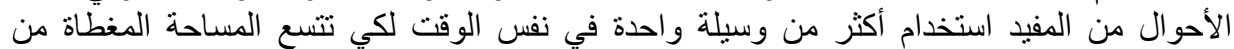

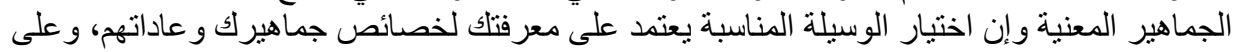

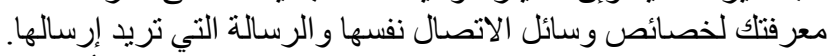

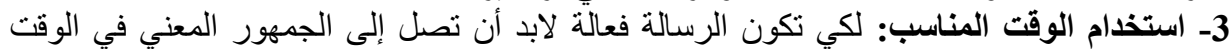

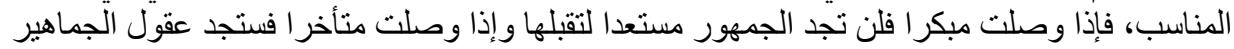
وقد فقدت الرغبة في الموضوع، وإن معرفة الوقت المناسب ينطلب معرفة بعادات الجماهير وبثقافاتها

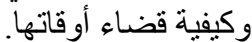

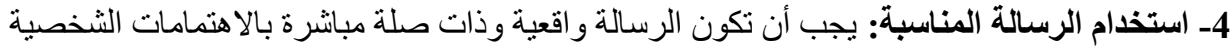

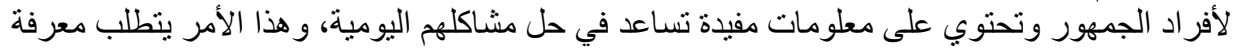

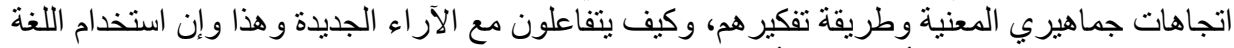

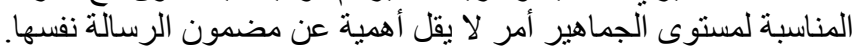

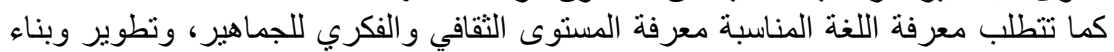

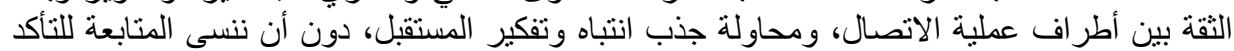

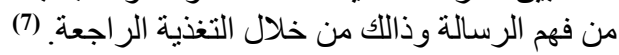

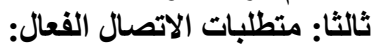

يعتبر الاتصال فعالا وناجحا إذا كان المعنى الذي في ذهن المرسل هو نفس المعنى الذي فسره المستقبل،

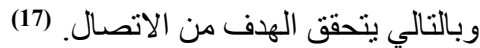

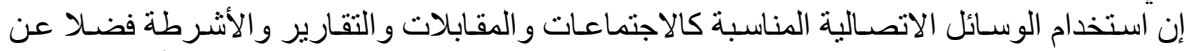

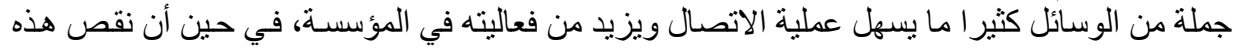

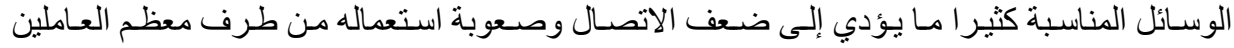

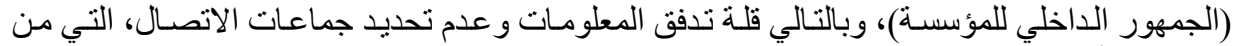
المفروض أن يتعرف عليها العمال حتى يتمكنو المن تلقي المعلومات اللازمة منها. (13) الأنيات 


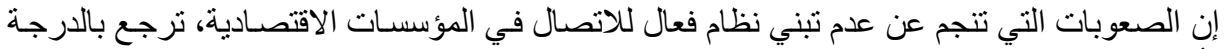

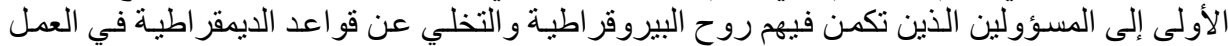

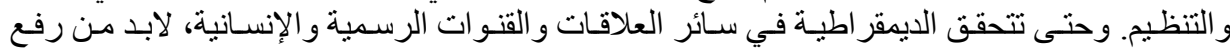
الحو اجز الهائلة بين الديمقر اطية والعمال ومن ينظم الصلة بين إثبات نسق الأوامر وبين التفكير في نسق لإنق

التنظيم. (51)

ويمكن إضافة جوانب أخرى من شأنها زيادة فعالية الاتصال في المؤسسة الاقتصادية وهي كما يلي:

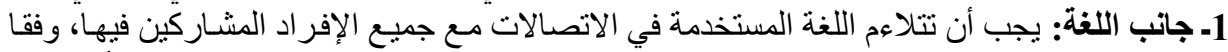

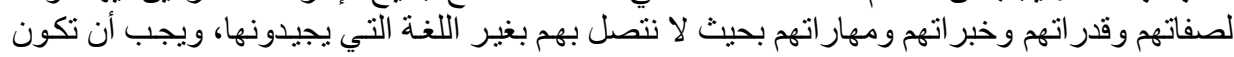

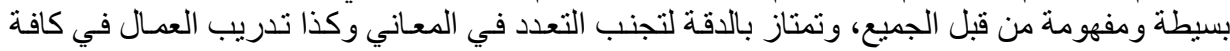
المستويات على استخدام اللغة في التعبير و الكتابة. 2ـ الجاتب الثقافي و الاجتماعي: حتى يكون الاتصال فعالا، يجب مر اعاة عدة معايير أهمها:

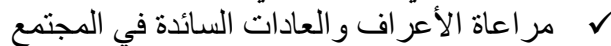

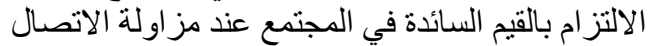

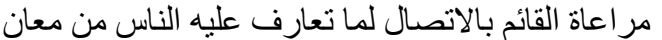

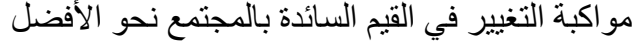

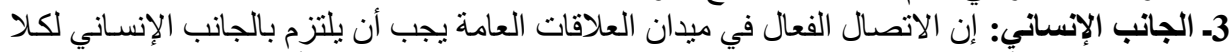

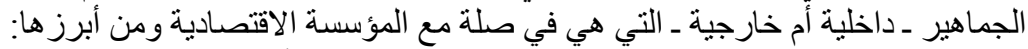

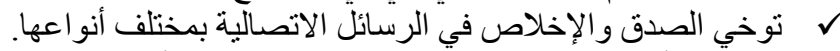

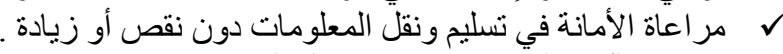

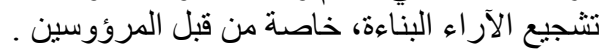

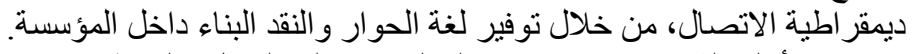

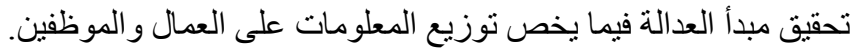

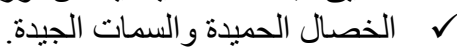

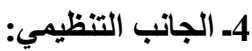

عدم إهمال الاتصال الغير الرسمي لأهميته في السير الطبيعي للعمل، و الحرص على الإسئل الاستفادة منه.

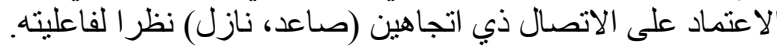

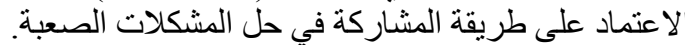

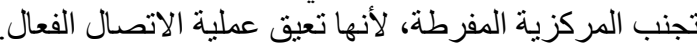

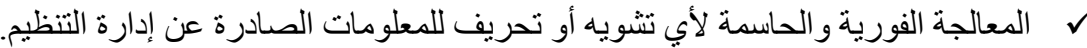

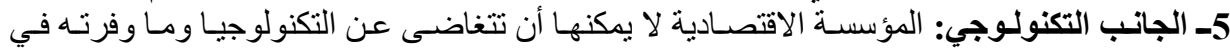

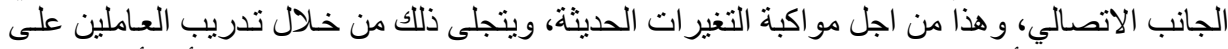

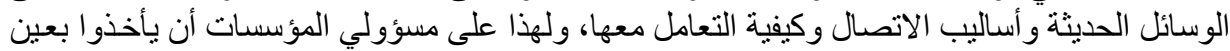

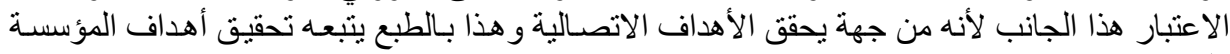
كلية. (9)

رابعا: أهداف المؤسسة الاقتصادية وخصائصها:

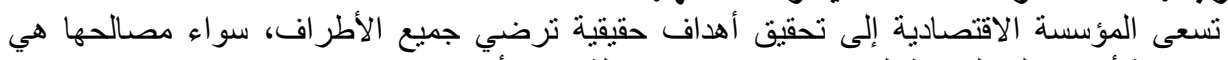

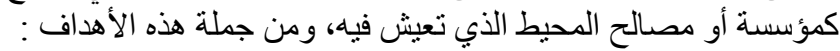

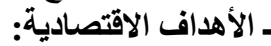

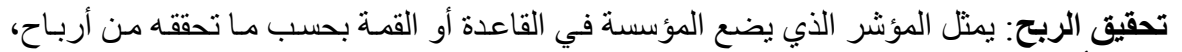

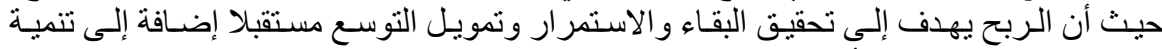
صورة جيدة للمؤسسة في أذهان المستثمرين. تحقيق منطلبات المجتمع: إن عملية تصريف المنتجات المادية و المعنوية للمؤسسة في السوق هي 
تلبية لحاجات المجتمع المتز ايدة، و من هنا يمكن القول أن المؤسسـة الاقتصسادية تحقق أهدافا أهمها تلبية رغبات المجتمع. ـ الأهداف الاجتماعية: يمكن تلخيصها فيماتئية يلي:

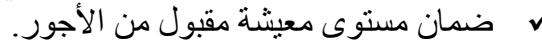

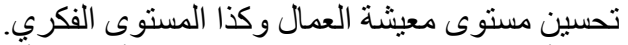

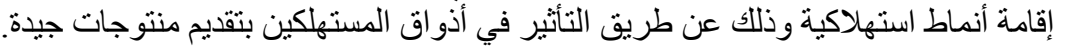

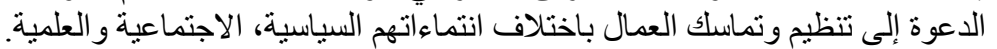

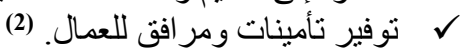
ـ الأهداف التكنولوجية: البحثث و التتمية من أجل تطوير منتجاتهاتها ومسايرة التطور التكنولوجي بالنسبة

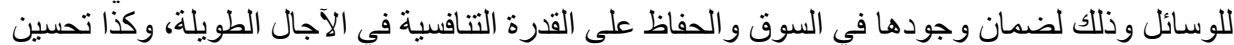

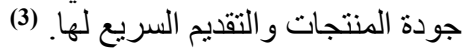
فالمؤسسة الناجحة هي التي تكيف أهدافها وفقا للمتغيرات و المستجدات التي تحدث في عالم المات الاقتصاد،

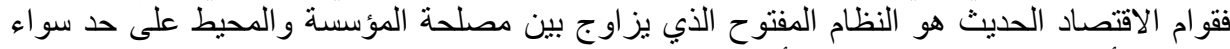
و هذا من أجل ضمان الوصول إلى الأهداف بكل نجاعة، ومن تم استقر ار وبقاء المؤسسة و عدم زو الها.

أما بخصوص خصائص المؤسسة الاقتصادية فيمكن تلخيصها في النقاط التالية:

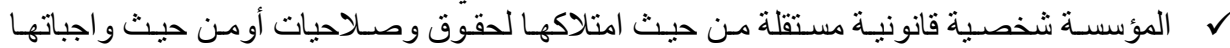
ومسؤولياتها.

القدرة على الإنتاج أو الوظيفة التي وجدات من أجلها.

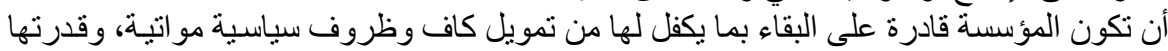

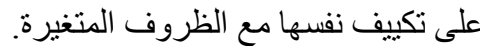

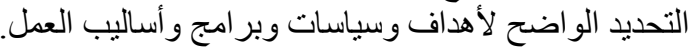
ضمان الموارد المالية لاستمر ار الفئ عملياتها.

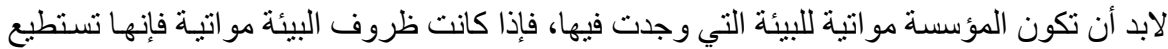

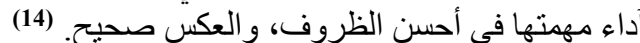
خامسا: خصائص المؤسسة الفهن ألفالة:

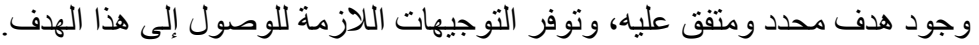

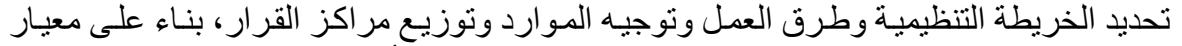

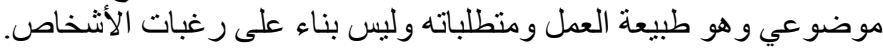

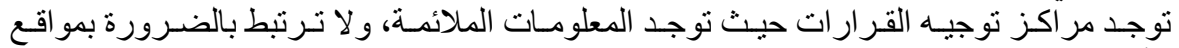
الأشخاص على الهيكل التنظيمي.

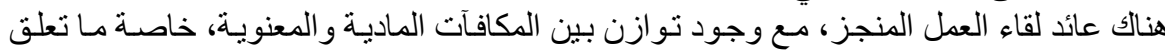

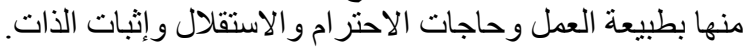

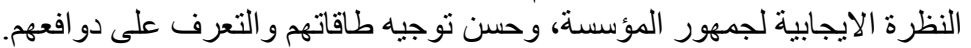

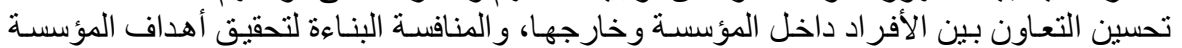

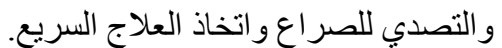

القياس الدقيق للانجاز ات و التعرف على نواحي القوة والضعف الضع وتحليل الأسباب وتطبيق الإجر اء

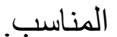

التطلع إلى فرض التحسين والبحث عن الجديد وتثجيع المبادرة والابتكار وانتشـار روح الاكتشـاف

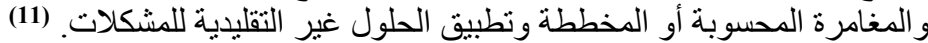

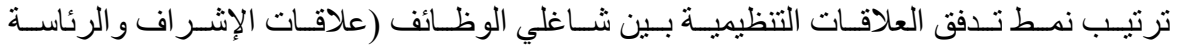

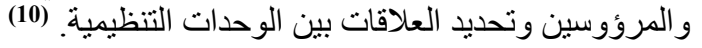


سادسا: العوامل المؤثرة على فعالية الاتصال في المؤسسة الاقتصادية:

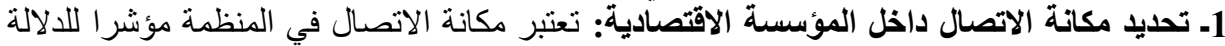

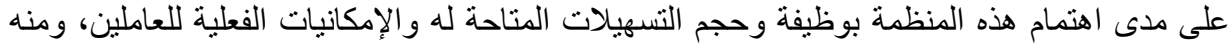

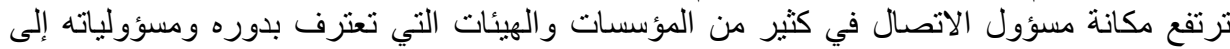

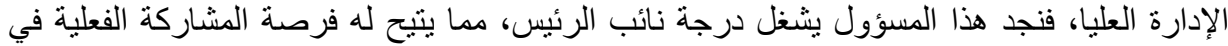

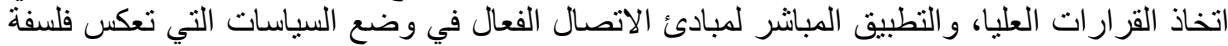

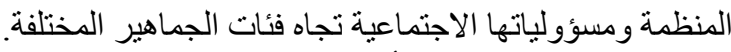

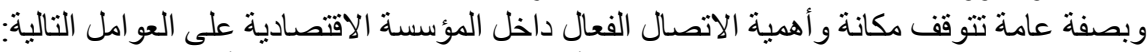

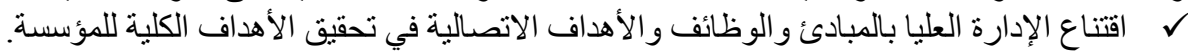

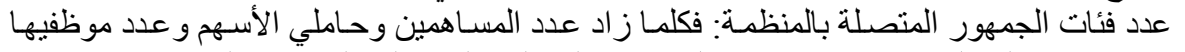

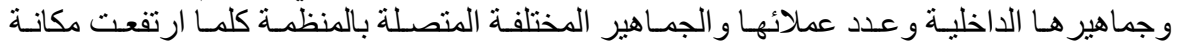
الاتصال إلى مستوى الإدارة العليا.

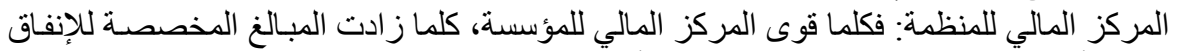

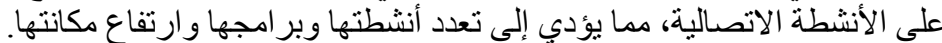

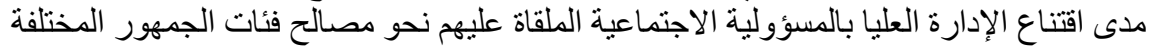

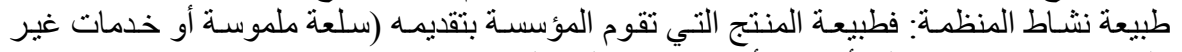
ملموسة) يؤثر ويؤكد على أهمية الأنشطة الاتصالية بالئية بالمؤسسة.

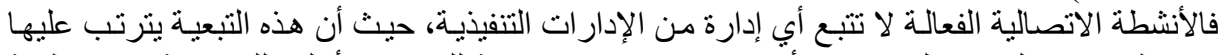

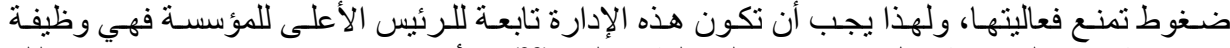

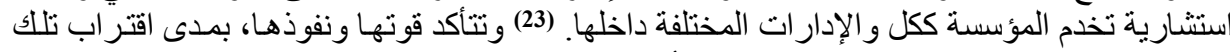

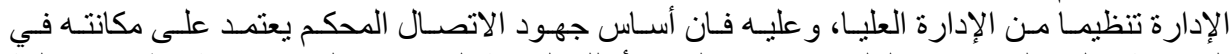

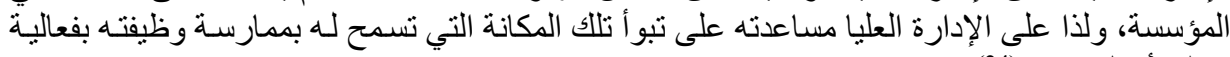

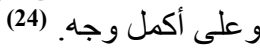

2ـ موقع الاتصال في الهيكل التنظيمي للمؤسسة الاقتصادية: لا يمكن أن يقوم الاتصال بوظيفته كما

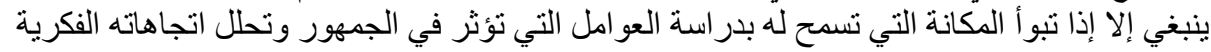

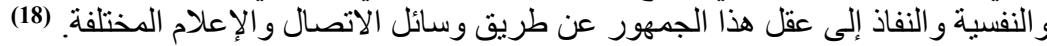
3ـ علاقة التأثير المتبادل بين المؤسسة والجئ والمحيط:

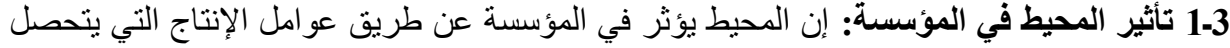

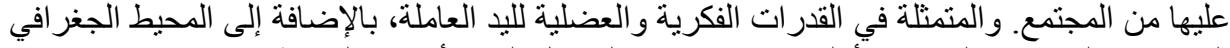

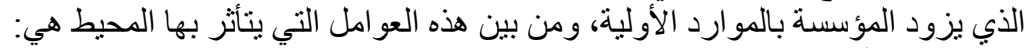

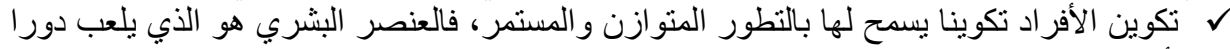
أساسيا في دورة حياة المؤسسة. ح الموارد الآولية التي تعتبر العنصر الهام في عملية نثاط المؤسسة.

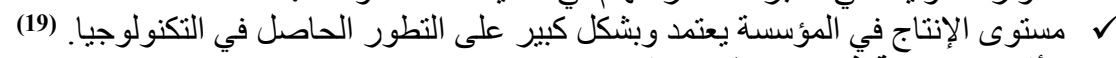

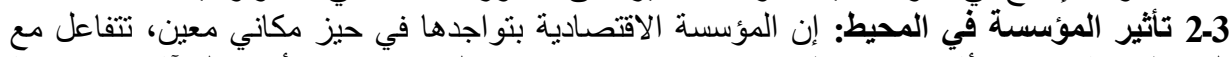

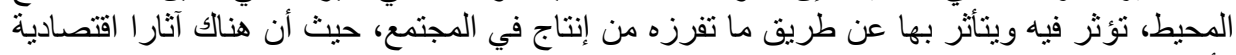

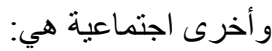

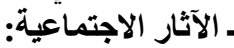
ل ل توفير الشغل عن طريق فتح المصانع و المؤسسات وبالتالي امتصاص البطالة.

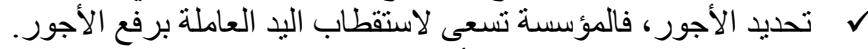

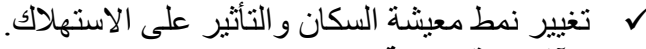
ـ الآثار الاقتصادية: 
دفع عجلة التعمير، وإعداد الطرق و المرافق العامة وظهور المنشآت التجارة وكذلك خلق التكامل الاقتصادي، فكل مؤسسة تحتاج إلى بلديتها.

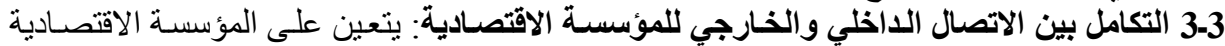

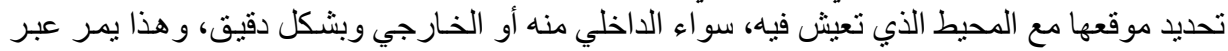

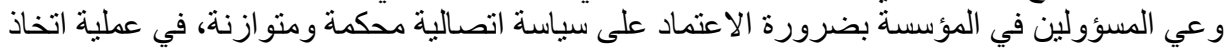

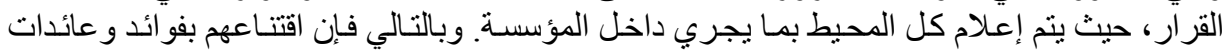

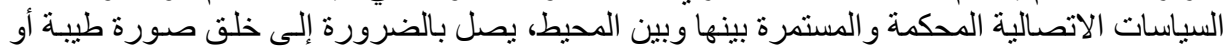

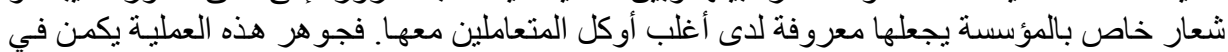

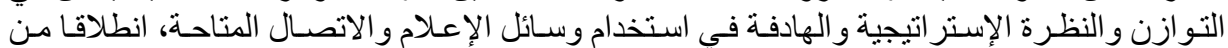

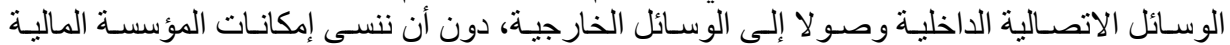

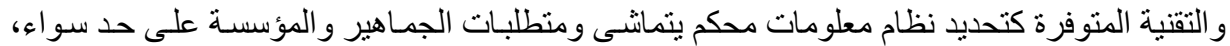
ووضع بر امج فعالة يثارك فيها مختلف المستويات من عمال ومؤطرين، بالإضافة إلى تكوين مختصين في مجال الاتصال و التنشيط.

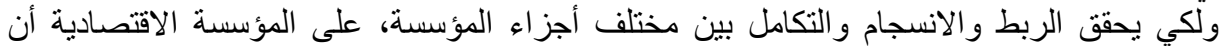

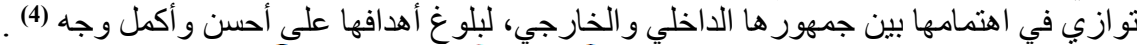

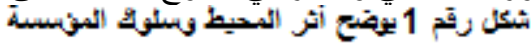

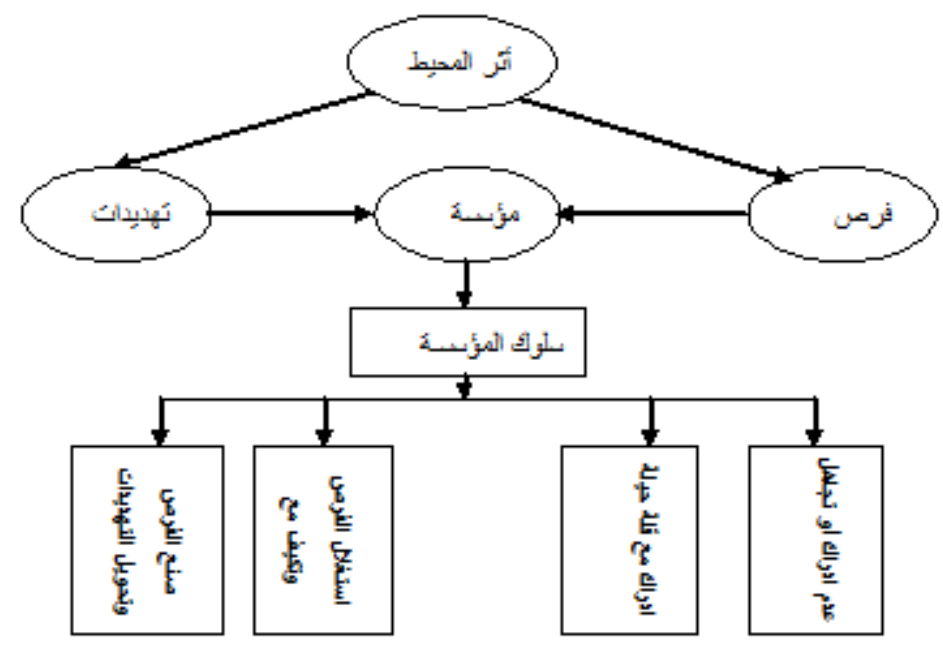

سابعا: فعالية المؤسسة الاقتصادية كنظام مفتوح:

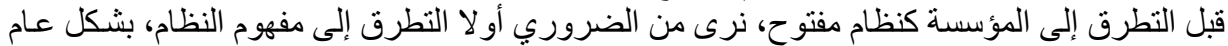

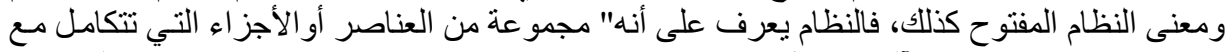

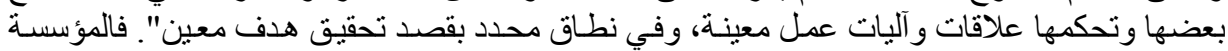

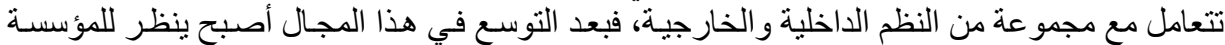

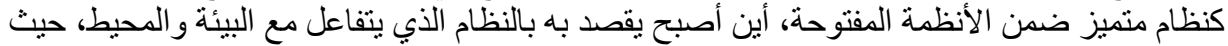

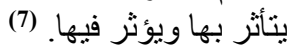
إن تحقبق فعالية وأهداف المؤسسة الاقتصادية كنظام وقدرتها على ذلك ترتبط بعام بعاملين: ـ البيئة أو المحيط أو التفاعلات البيئية التي تؤثر في عملها. 
ـ قدرنها على التكيف مع هذه البيئة.

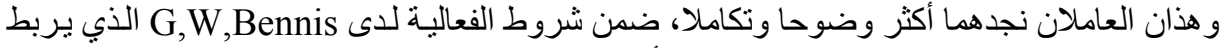
صحة المؤسسة بشروط الفعالية التي يقسمها إلى أربعة وهئ وهي:

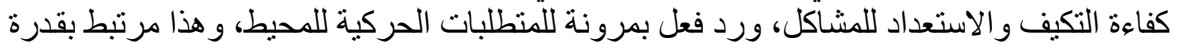

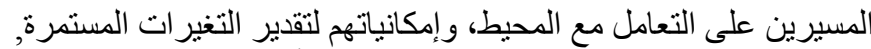

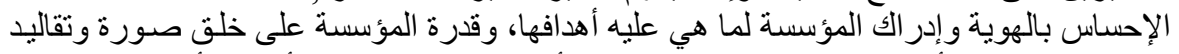

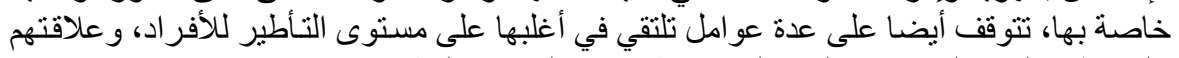

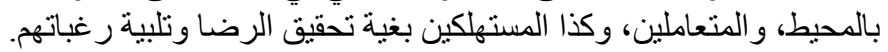

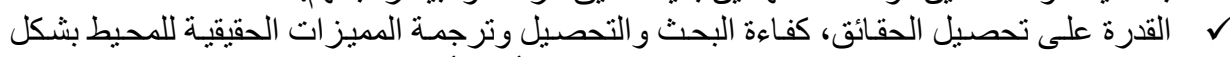

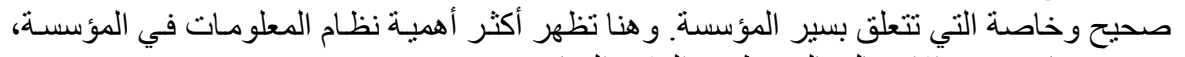

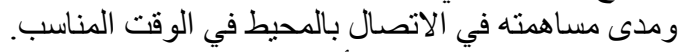

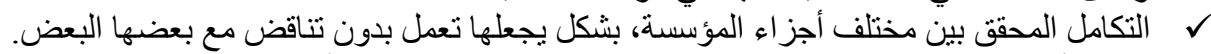

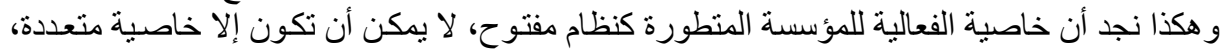
تحتوي على قدرتها على التكيف و التنسيق الداخلي و الخارجي للمؤسسة الاقتصنية لادية.

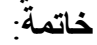

يتنين لنا من خلال ما سبق أن المؤسسة الاقتصادية، لم تعد تعتمد على تلك النظرة الأحادية و الذاتية التي

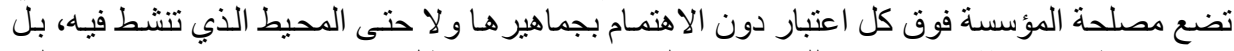

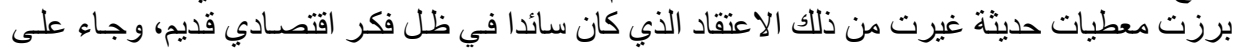

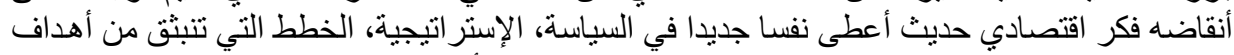

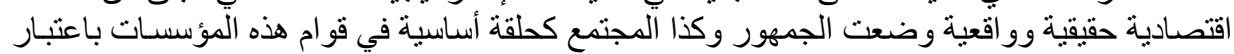

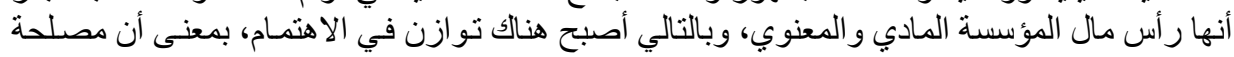

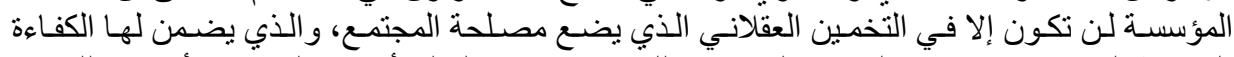

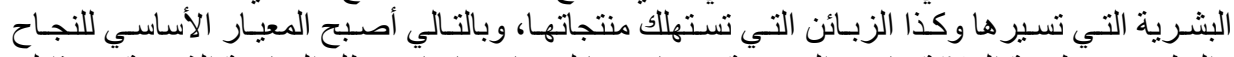

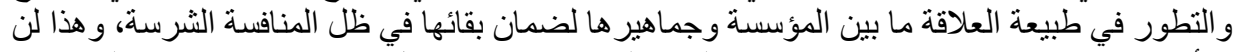

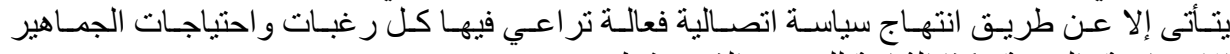

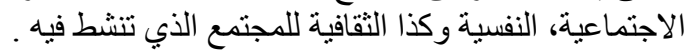

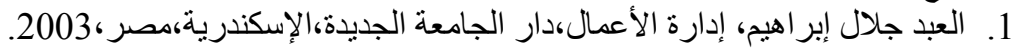

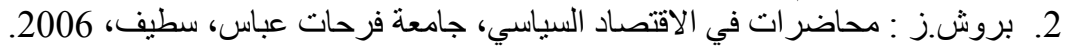
3. ثابت عبد الرحمن إدريس، جمال الدين المرسي: الإدارة الاستر اتيجية: مفاهيم ونماذج تطبيقية،

4. خالص صافي صالح، رقابة تسيير المؤسسة في ظل اقتصاد السوق، ديوان المطبو عات

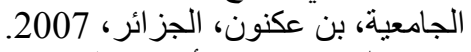

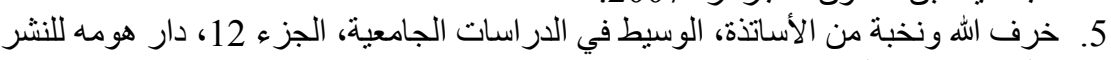

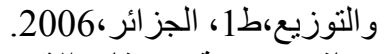

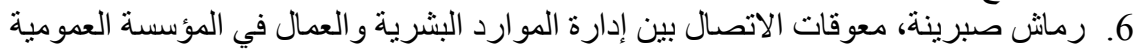

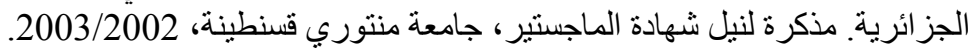

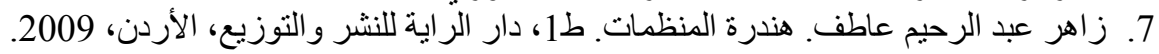
8. سحر محمد وهبي: بحوث جامعية في الإعلام والاتصـال، دار الفجـر للنشر و التوزيع، الأردي،

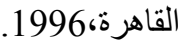
9. شعبان فرج، الاتصالات الادارية، دار أسامة للنشر والتوزيع،11، عمان، 2009. 


$$
\text { 10.شُوان علي شيبه، العلاقات العامة بين النظرية و التطبيق. دار المعرفة الجامعية. }
$$

11.صالح بن نوار: الفعالية التنظيمية داخا المؤسسة الصناعية من وجهة نظر المديرين والمشرفين،

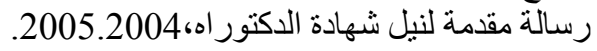

12. عبد الرزاق بن حبيب، اقتصاد وتسبير المؤسسة، ديو ان المطبو عات الجامعية، بن عكنون،

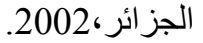

13.علي سعيداني، بيروقراطية الإدارة الجزائرية، الثركة الوطنية للنشر والتوزيع، الجزائر، .1981

14.عمر صخري. اقتصاد المؤسسة. ديوان المطبو عات الجامعية. ط4. بن عكنون. الجزائر. 2006

15.قباري محمد إسماعيل، علم الاجتماع الصناعي ومشكلات الإدارة و التنمية الاقتصادية، ط1،دار

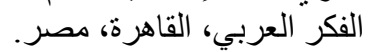

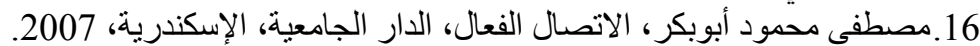

17.معن محمود عياصرة، القيادة و الرقابة والاتصال الاداري، دار الإدية الحامد للنشر و التوزيع،ط1،

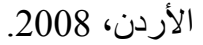

18.محمد رفيق الطيب، مدخل للتسيير (أساسيات، وظائف، تقتيات)،ديوان المطبو عات الجامعية،

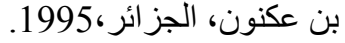

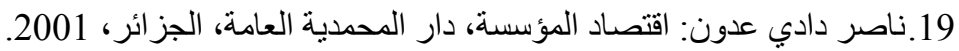
20.ناصر دادي عدون. الاتصال ودوره في كفاءة المؤسسة الاقتصادية، دار المحمدية العامة، الجائ،

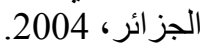

21.Manuel de la commission, Relation publique: Rotary International.

22.Approche systémique et éducation relative à l'environnement TARA ARTIC,8 Académie de Paris 2007-2008

23.http://www.trackbusters.fr/definition-client.html 11H00 2009 /04/03 $\mathrm{PDF} /$

Bernard Dagenais: Le plan de communication (l'art de séduire et convaincre les autres), les presses de l'université Laval, Québec, 